\title{
Mineração
}

\section{Diagnóstico dos garimpos de topázio imperial no Alto Maracujá, Sub-bacia do rio das Velhas, MG}

\author{
Robson José Peixoto \\ Mestrando do Programa de Pós-Graduação em Engenharia Mineral \\ Departamento de Engenharia de Minas/EM/UFOP \\ E-mail: robson@intercampo.com.br
}

Hernani Mota de Lima

Professor Adjunto do Departamento de Engenharia de Minas/EM/UFOP

E-mail:hernani@demin.ufop.br

\section{Resumo}

Esse estudo apresenta um diagnóstico dos garimpos de topázio imperial na cabeceira do rio Maracujá, denominada Alto Maracujá, em Cachoeira do Campo, distrito de Ouro Preto, Minas Gerais. Há muitos anos atuante na região, o garimpo é acusado de afetar seriamente a infra-estrutura e o meio ambiente da região, com destaque para os impactos na drenagem e nas matas ciliares. Para realização do diagnóstico ambiental da atividade garimpeira na região, utilizaram-se técnicas de avaliação de impacto ambiental, visitas a campo, entrevistas, levantamento da literatura técnica e histórica da região e localização dos garimpos via GPS. O estudo apresenta os efeitos no meio ambiente e infra-estrutura, bem como a interação sócio-econômica da atividade na região.

Palavras-chave: topázio imperial, garimpos, avaliação de impacto.

\begin{abstract}
This study presents a diagnosis of the imperial topaz artisanal mining (garimpo) at the head of Maracujá river, called high Maracujá, Cachoeira do Campo, district of Ouro Preto, Minas Gerais. Operating in this region for a long time, the garimpo is accused of seriously affecting the infrastructure and the environment of the region with emphasis on natural drainage and levee's forest impacts. To conduct the environmental diagnosis of the garimpos activity in the region it was used environmental assessment techniques, field trips, interviews, historic literature research and GPS survey of the garimpos. This study presents the effects on the environment and infrastructure as well as the socioeconomic interaction of this activity in the region.
\end{abstract}

Keywords: Imperial topaz, artisanal mining, environmental assessment techniques. 


\section{Introdução}

Segundo Miranda et al. (1997), a atividade garimpeira é uma forma muito antiga de extração mineral. Provavelmente remonta ao século XV através do avanço dos europeus sobre terras desconhecidas como aconteceu no continente americano. Essa atividade pode ser considerada uma modalidade marginal à mineração, encarada pela sociedade como símbolo de desorganização, violência, insegurança, insalubridade, problemas sociais, degradação ambiental e a total falta de técnica para a explotação dos bens minerais. Os garimpos trazem sérios danos ao meio ambiente (IBRAM, 1992).

\section{Material e métodos}

A metodologia utilizada para a realização desse trabalho consistiu em observações de campo, análise de documentos, levantamento de bibliografia técnica e histórica, depoimentos de pessoas ligadas direta ou indiretamente ao garimpo, entre outros expedientes que se fizeram necessários para melhor avaliação do problema.

\section{Resultados \\ 3.10 topázio imperial}

O topázio imperial é o principal objetivo da atividade garimpeira do Alto Maracujá. Trata-se de uma gema rara no mundo, de alto valor econômico, atualmente encontrada somente na região de Ouro Preto (Gandini, 1994). Castañeda et al. (2001) afirma que o topázio imperial foi descoberto por volta de 1772, no local denominado Morro de Saramenha, em Ouro Preto. Com o passar do tempo, a extração dessa gema foi evoluindo e diversos depósitos vêm sendo trabalhados dentro dessa região como as minas do Vermelhão em Saramenha e a do Ca- pão do Lana (maior em produtividade e totalmente mecanizada), em Rodrigo Silva (Sauer et al., 1996). Outras áreas de ocorrência do topázio imperial se caracterizam pela presença de pequenos garimpos de aluvião, grande parte deles, ilegais. A Figura 1 mostra a localização das ocorrências e locais de extração de topázio imperial.

\subsection{O Rio Maracujá}

O rio Maracujá é afluente da margem esquerda do rio das Velhas, um dos principais afluentes do rio São Francisco. Formado pelos córregos Cipó, Arranchador e Caxambu, o Maracujá banha o maior distrito de Ouro Preto, Cachoeira do Campo. Trata-se de um rio de extrema importância para a região, dotado de grande valor histórico e físico, como atesta Ramos ([196_]).

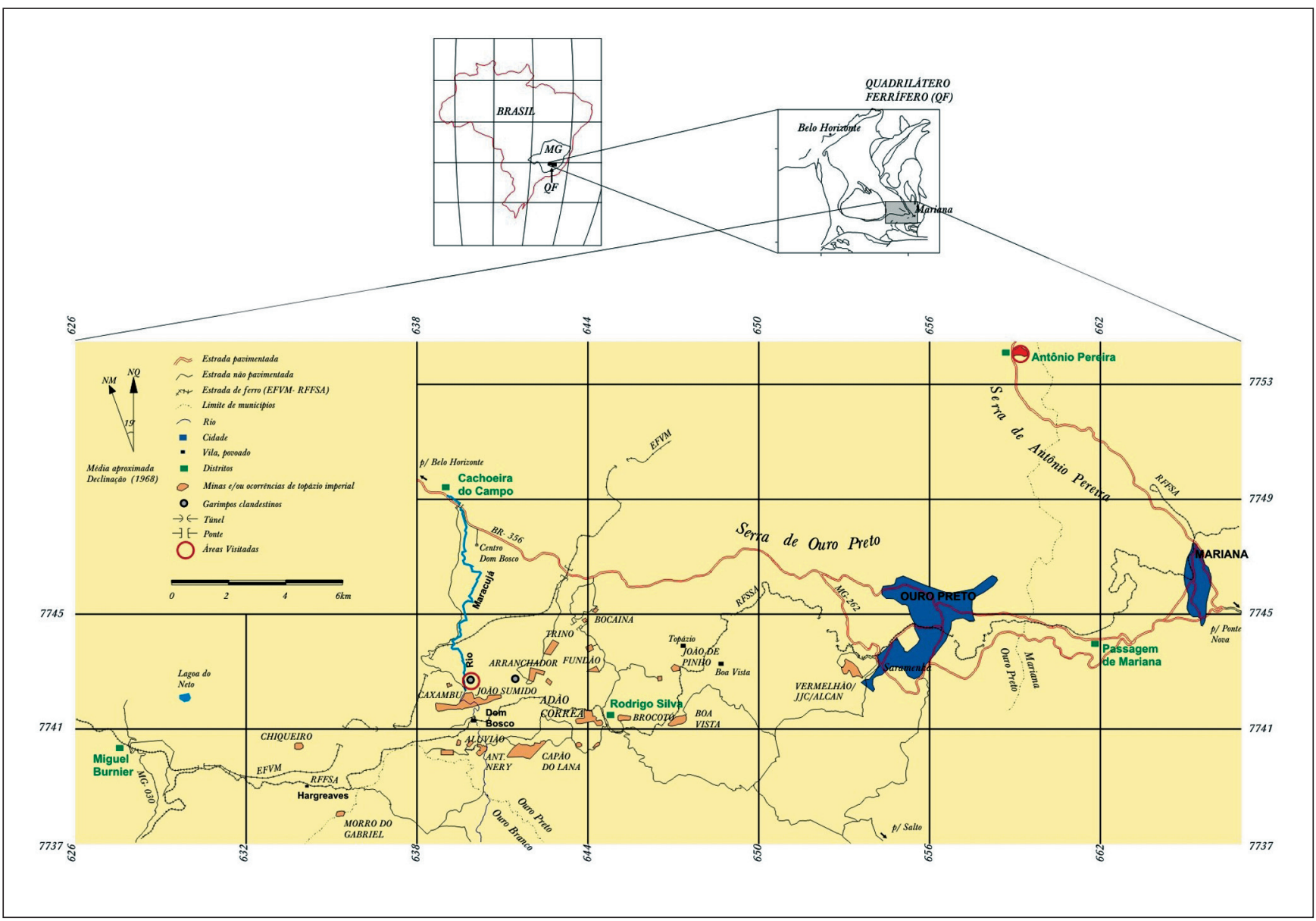

Figura 1 - Minas e ocorrências de topázio imperial na região de Ouro Preto e Antônio Pereira (modificado de Gandini, 1994). 
Robson José Peixoto et al.

\subsection{Atividade garimpeira no Alto Maracujá}

A atividade de mineração está muito presente no Alto Maracujá com os garimpos de topázio imperial. Pequenas empresas extrativas legais e garimpos individuais ilegais se estabeleceram no local, principalmente, a partir da década de 70 do século XX, quando houve uma intensificação dos garimpos de topázio na região de Ouro Preto.

\subsection{Garimpos clandestinos}

Os garimpos clandestinos ou manuais de topázio imperial podem ser divididos em dois tipos específicos: o garimpo de margem e o de leito. Entretanto, na maioria das vezes, esses tipos se confundem no campo. A seguir são descritos os diversos tipos identificados durante esse estudo.

\subsubsection{Garimpo de margem}

A Figura 2 mostra um esquema de um garimpo de margem. Primeiramente há o desmatamento para a retirada da camada de solo orgânico. Seqüencialmente, o decapeamento culmina com a remoção dos horizontes superficiais do solo, de modo a dar ao garimpeiro acesso às camadas mineralizadas e preparar a área para a lavra em profundidade. $\mathrm{O}$ decapeamento pode ser desenvolvido por meio de enxadas, enxadões e picaretas.

A abertura da frente de lavra é a fase posterior ao decapeamento, onde os garimpeiros procuram, conforme a necessidade, expandir horizontal e verticalmente sua área de atuação, escavando horizontes mais profundos de solo e as camadas mineralizadas denominadas cascalho. Essas camadas, mais resistentes ao avanço da lavra, são formadas pelas rochas com veios de quartzo onde há a ocorrência do topázio imperial. A profundidade das escavações, tomandose como nível de referência o topo do horizonte A do solo, varia muito, podendo atingir de 2 a 7 metros em média. Os cortes são abertos em taludes de 90 graus ou taludes irregulares negativos. As fer- ramentas utilizadas nas aberturas das frentes de lavra são picaretas, enxadas, enxadões e a inusitada enxada-pá (cabo de enxada e na extremidade uma pá disposta em ângulo de 90 graus com o cabo). A Figura 3 ilustra uma frente de lavra na margem do córrego Cipó.

Para a retirada da água que se acumula nas frentes de lavra devido à proximidade do lençol freático, os garimpeiros usam, como subterfúgio, longas mangueiras de 10, 20 metros ou mais de comprimento com diâmetros de 1" e 1,5", estendidas em direção à jusante do córrego Cipó, para sugar a água da abertura produzida.
O cascalho mineralizado é retirado das frentes de lavra e transportado até as margens do córrego por meio de carrinhos de mão ou latas ou galões de plástico. Para a lavagem do cascalho, o garimpeiro se vale de uma peneira de pedreiro ou uma maior, construída por ele próprio com a finalidade de facilitar a cata do topázio imperial.

\subsubsection{Garimpo de leito}

Esse tipo de garimpo é executado diretamente no leito do córrego ou próximo à margem desse. A Figura 4 mostra a configuração de um garimpo de leito.

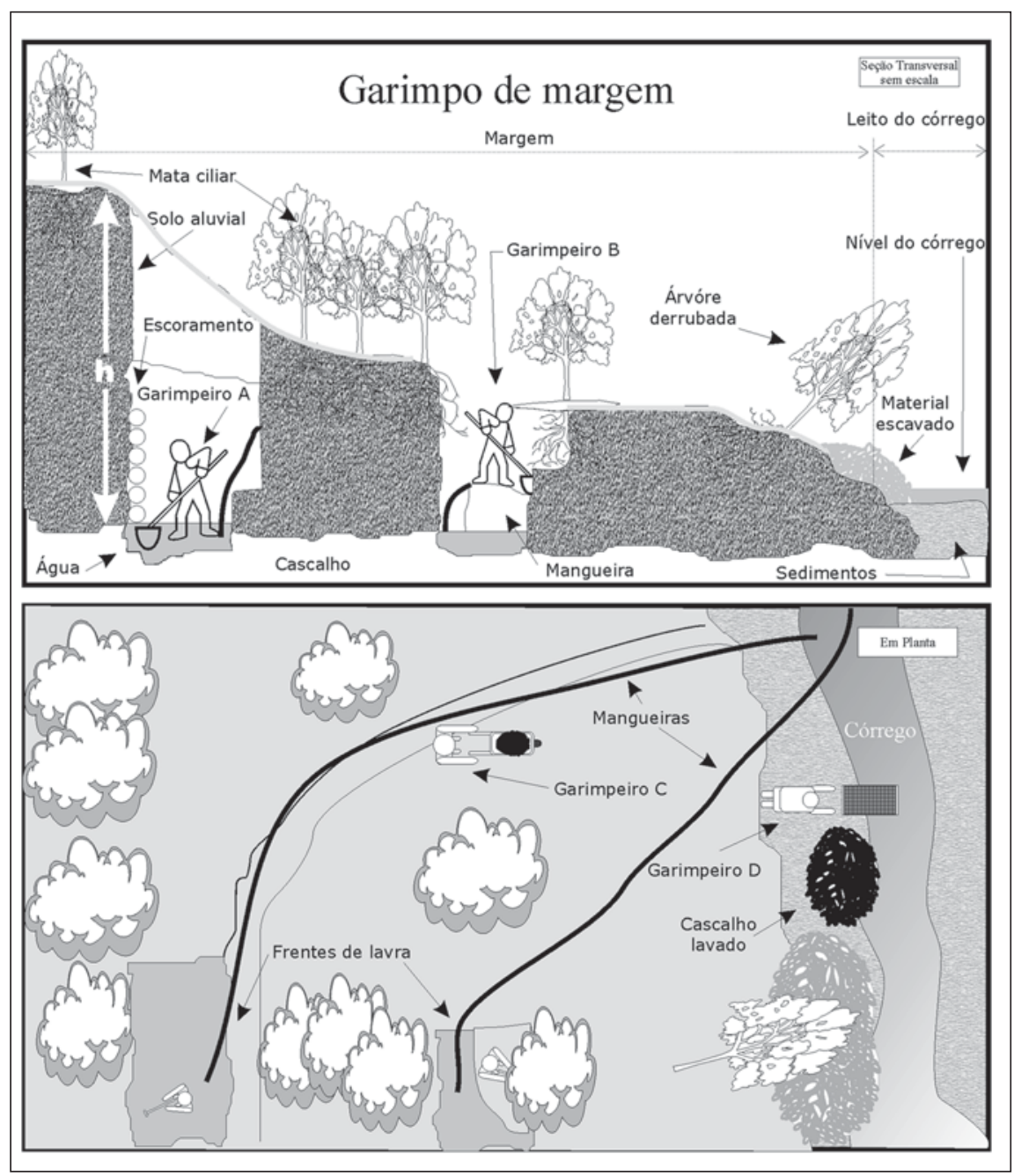

Figura 2 - Esquema de um garimpo de margem no Alto Cipó. O garimpeiro A escava o terreno até a rocha, chamada de cascalho. A altura $\mathrm{h}$ pode variar de 2 a 7 metros aproximadamente. O garimpeiro $\mathrm{B}$ faz o desmatamento, derrubando a árvore pela raiz, e o decapeamento. O garimpeiro $C$ leva o cascalho mais o solo escavado para ser lavado à beira do córrego Cipó. O garimpeiro $D$ coloca o cascalho em uma peneira, faz a lavagem e a cata do topázio. 
Desconsiderando o desmatamento e o decapeamento, basicamente comporta as mesmas operações realizadas nos de margem. Tem como diferencial o maior volume de água acumulado nas frentes de lavra e a instabilidade dos taludes escavados no leito do córrego. A Figura 5 mostra uma frente de lavra no leito do córrego Cipó, no Alto Cipó.

Em outra forma de garimpo de leito são utilizadas dragas para aumentar o rendimento da produção. A Figura 6 ilustra como é feito o trabalho de dragagem. $\mathrm{O}$ cascalho, juntamente com lama e água, é dragado da área de escavação e jogado contra a superfície de uma peneira. $O$ garimpeiro realiza a cata do topázio na superfície da peneira. A Figura 7 mostra uma frente de lavra no Alto Cipó com uso de draga abandonada temporariamente.

\section{Discussão}

\subsection{Impactos ambientais}

As operações que constituem um garimpo de topázio imperial trazem uma série de impactos para o ambiente de entorno. $\mathrm{O}$ desmatamento, o decapeamento e a abertura das frentes de lavra destroem ou alteram a diversidade da mata ciliar e interferem na fauna local. Além disso, o decapeamento e a abertura de frentes de lavra elevam os impactos negativos na drenagem do córrego Cipó a níveis preocupantes em escala local e regional. Pilhas de estéril ficam expostas à ação do escoamento superficial e ao transporte de sólidos sedimentáveis. Principalmente, no período das cheias, ocorre o deslocamento dos sólidos rumo à jusante do Cipó, acarretando um alto grau de assoreamento deste, como pode ser verificado na Figura 8.

Quando a lavra do topázio imperial é realizada por dragagem, a geração de sólidos sedimentáveis torna a operação extremamente danosa ao córrego Cipó, devido ao aumento expressivo do nível de turbidez das águas deste. Nota-se, também, uma contribuição considerável desse processo no assoreamento à jusante.

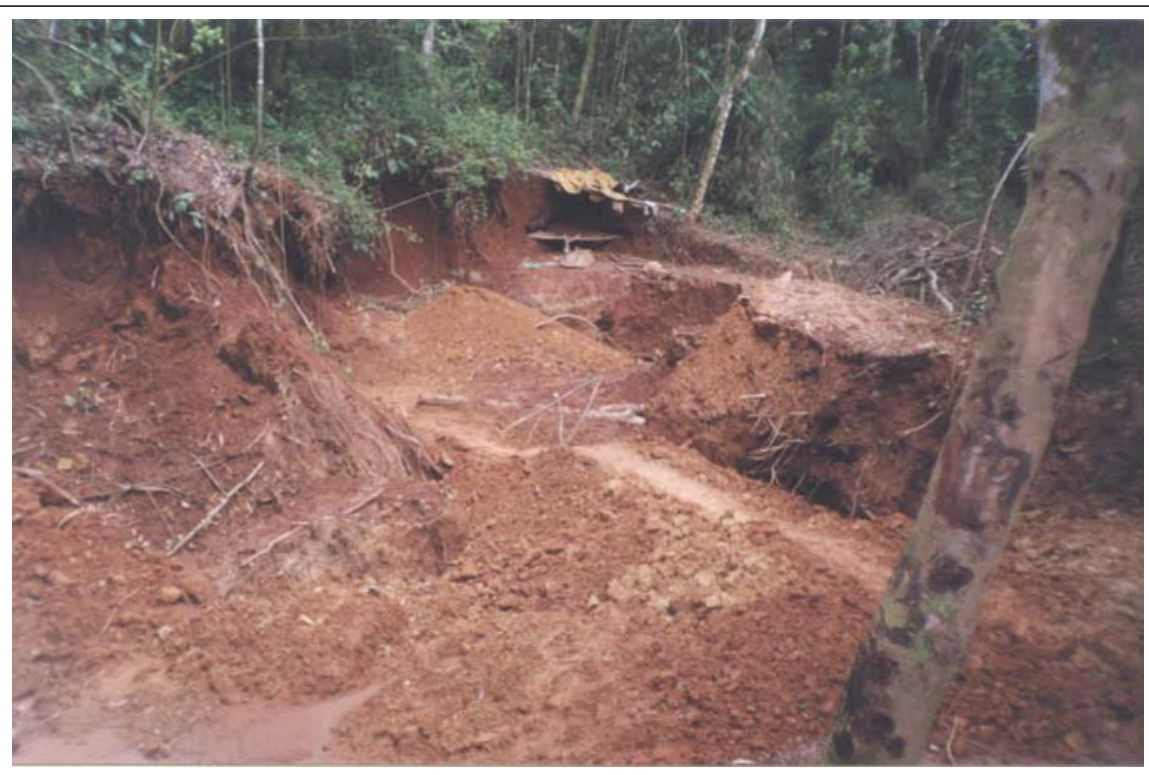

Figura 3 - Frente de lavra aberta na margem do córrego Cipó, na região denominada Alto Cipó.
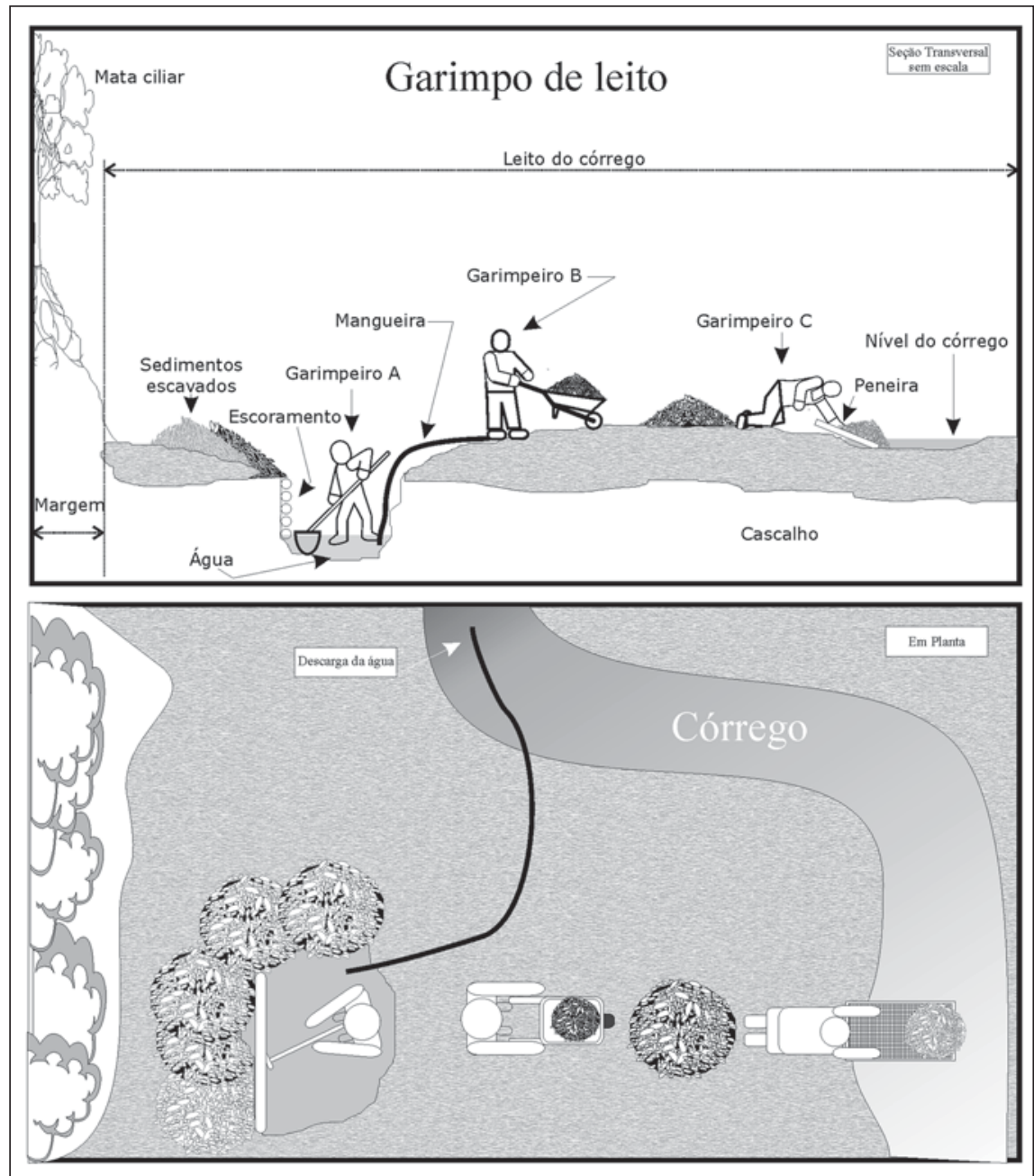

Figura 4 - Esquema de um garimpo de leito. O garimpeiro $A$ escava o leito do rio e retira o cascalho com lama. $O$ garimpeiro $B$ transporta o material até um filete de água corrente. $O$ garimpeiro $\mathrm{C}$ recebe o material e o lava numa peneira para posterior cata do topázio imperial. 
O esgotamento das águas acumuladas nas frentes de lavra, se feito por mangueiras, causa apenas impacto visual. Porém, se realizado com o auxílio de pequenas dragas, causa impactos imediatos ao curso d'água, devido ao aumento da turbidez deste.

Na lavagem do cascalho, a contaminação do curso d'água se dá pelo passante da peneira onde todo o material é manipulado, aumentando a concentração de finos e, conseqüentemente, o nível de turbidez das águas do córrego Cipó. Quando o garimpeiro se vale da construção de barramentos para o represamento das águas do córrego para posterior lavagem do cascalho, isto resulta na interferência do fluxo normal das águas e no impacto visual negativo.

A cata do topázio permite a formação de pilhas de rejeito compostas pelo descarte do cascalho, que contribuem para o assoreamento do córrego no período chuvoso. Seqüências de pilhas ao longo do leito do córrego interferem no fluxo normal de suas águas, na sua morfologia e contribuem para o impacto visual negativo no local.

O abandono temporário das frentes de lavra, seja na margem ou leito do córrego, é uma das ações mais freqüentemente efetuadas pelos garimpeiros. Em geral, costuma-se associar essa prática ao insucesso da lavra ou tática do garimpeiro para escapar da fiscalização ambiental. Os constantes abandonos e retomadas de frentes de lavra impedem a recuperação natural do local afetado.

\subsection{Questões sociais, de saúde e de segurança}

Além dos impactos diretos e indiretos ao meio ambiente, questões voltadas ao próprio garimpeiro e sua relação com a atividade e o entorno foram consideradas nesse estudo. Esse tipo de atividade predispõe o trabalhador a constantes ameaças à sua integridade física, tais como doenças ocupacionais, desmoronamentos, traumas, quedas, etc. Risco maior é exposto àqueles indivíduos não garimpeiros que circulam desavisados pelo local.

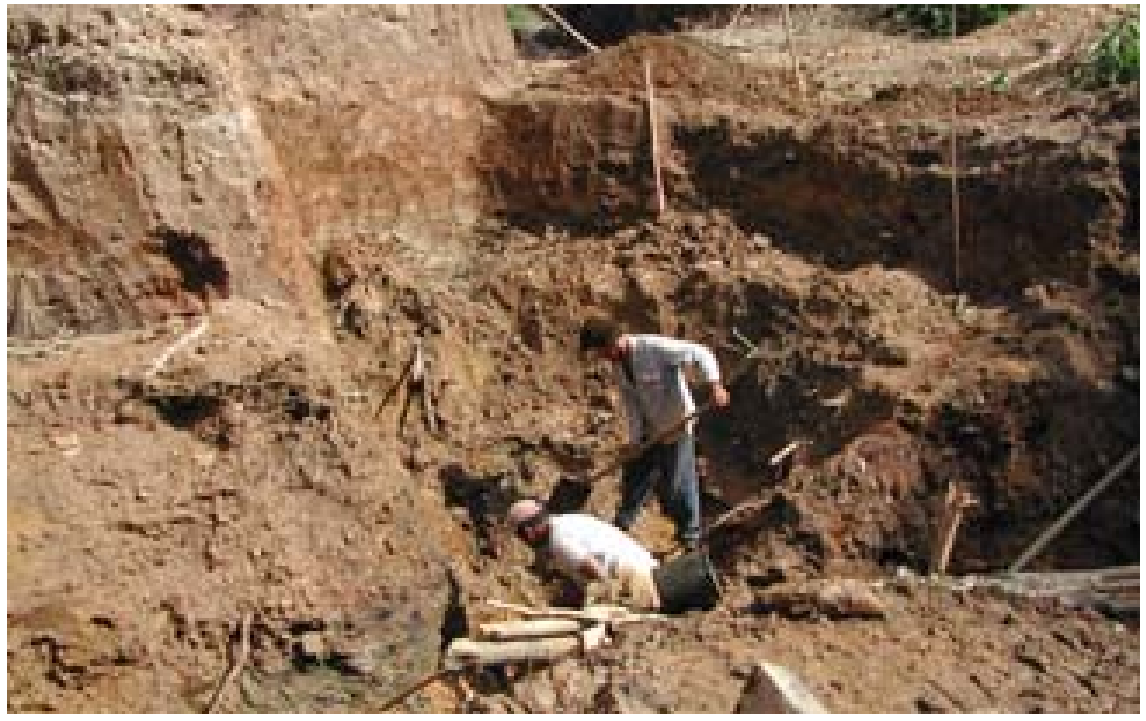

Figura 5 - Esse garimpo de leito no Alto Cipó abrange parte da margem. O talude do lado da margem (de frente para os garimpeiros) se apresenta mais estável que o do lado do córrego (lado do braço esquerdo do garimpeiro de camisa branca e boné claro).

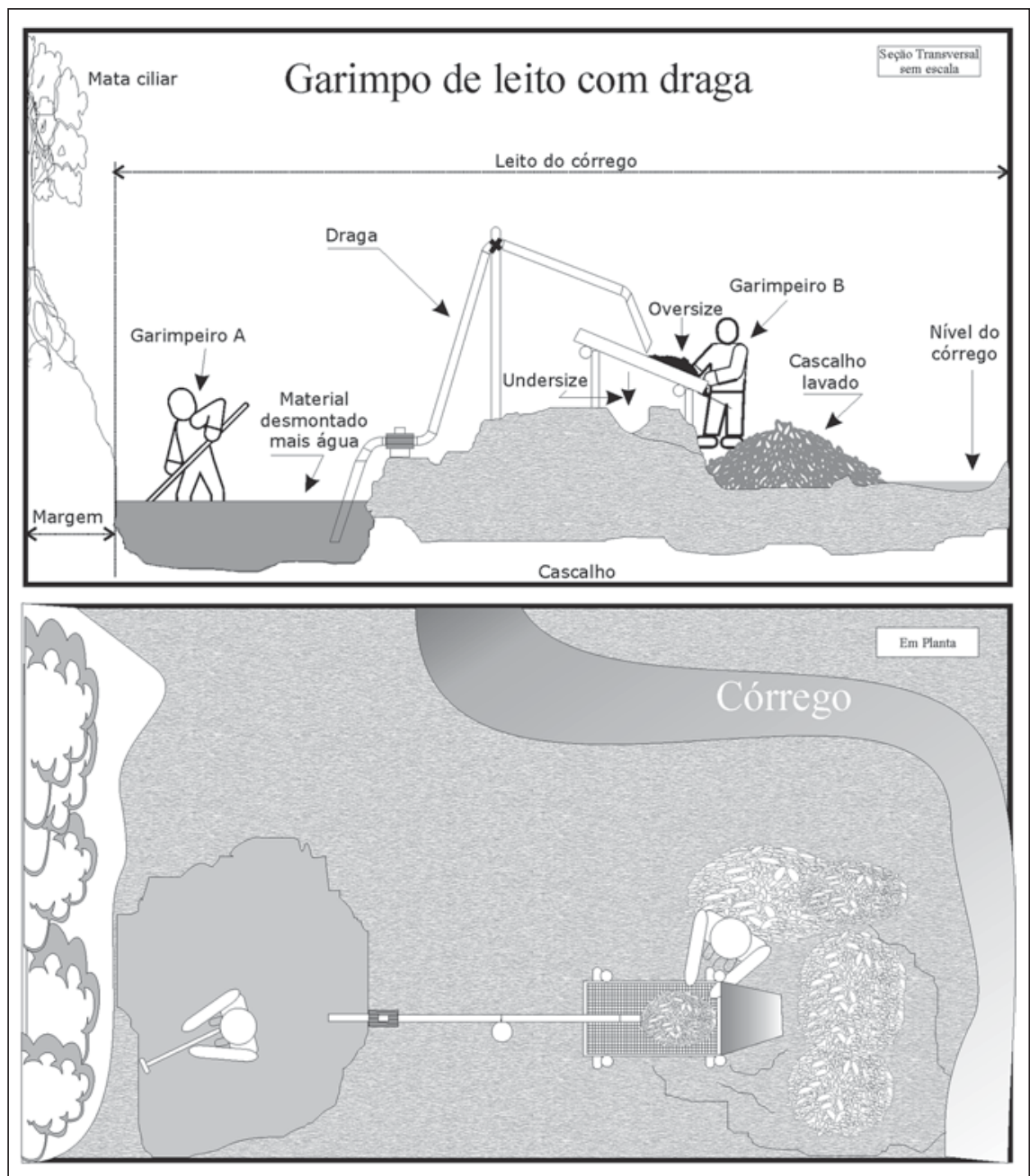

Figura 6 - Esquema de um garimpo de leito, onde o garimpeiro A escava o material formando uma abertura de diâmetro maior e o garimpeiro $B$ faz a cata do cascalho extraído pela draga juntamente com lama. 


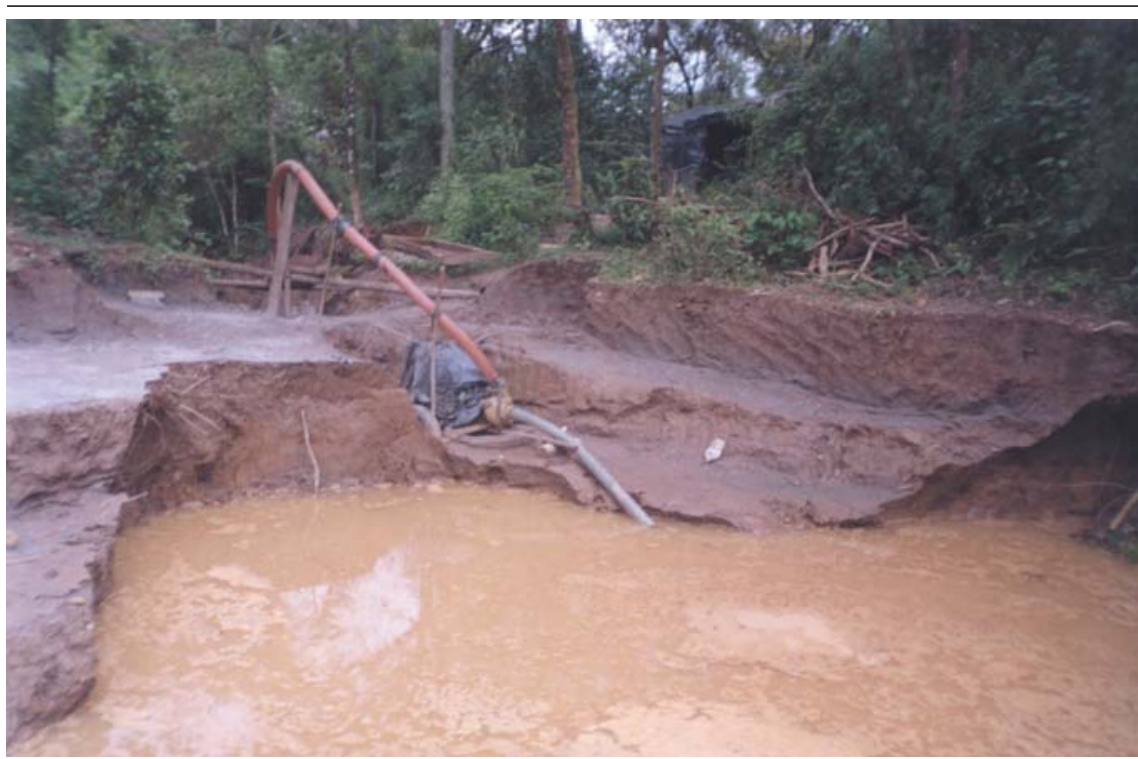

Figura 7 - Vista de uma frente de garimpo de leito com draga no Alto Cipó. A foto mostra o lado onde é feita a escavação do material.

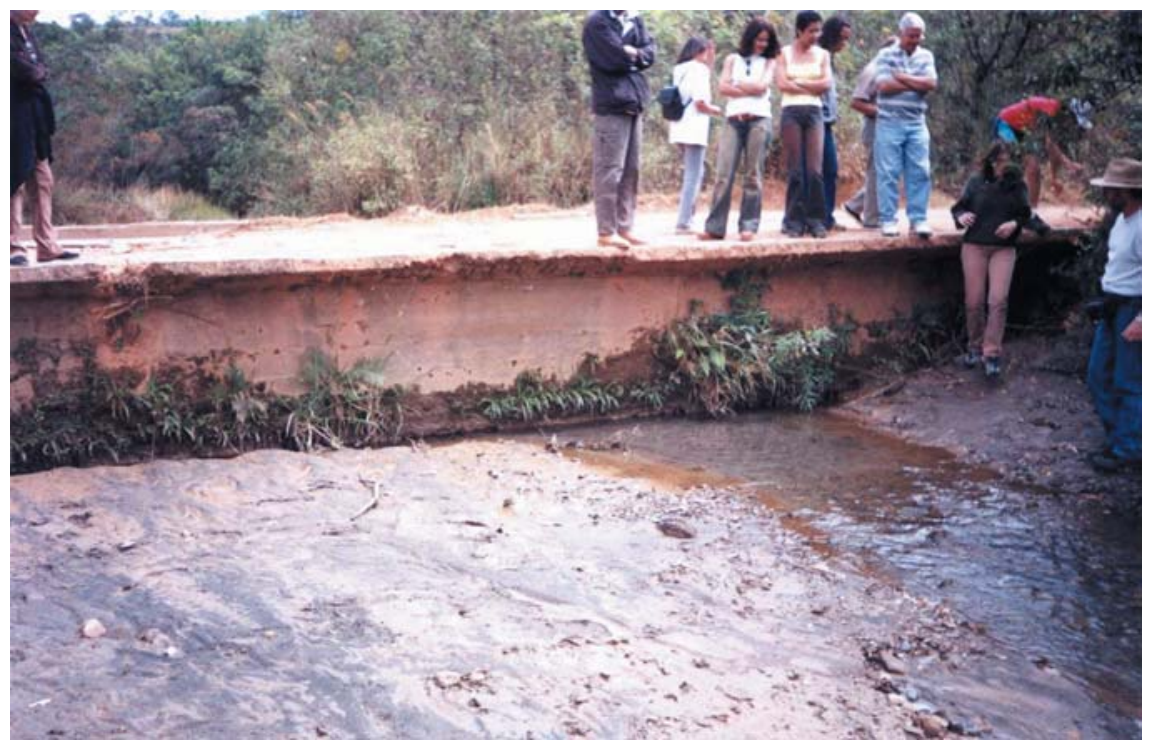

Figura 8 - Detalhe do grau de assoreamento na Ponte do Morro da Mata sobre o córrego Cipó.

Conflitos entre garimpeiros e entre estes e indivíduos externos ao garimpo são freqüentes, em alguns casos, resultando em morte. Em muitos momentos, tensões com donos de terras ou órgãos fiscalizadores desencadeiam situações desagradáveis a ambas as partes, levando o local a um estado crítico.

Ameaças a obras civis na região também são fatos reais devido ao volume de impactos gerados nos garimpos de topázio imperial. São comuns erosões

\section{Conclusões}

As atuais condições do garimpo de topázio imperial no Alto Maracujá comprometem o ecossistema da região e a infra-estrutura pública. Caso não ocorra uma organização da atividade sob a forma de cooperativa ou associação, tornase impossível solucionar o problema e recomenda-se a paralisação imediata do garimpo.

Não há estudo que comprove a dependência econômica da atividade por todos os garimpeiros que atuam na região. Sabe-se que muitos são esporádicos e se beneficiam do garimpo como um instrumento de renda extra. Entretanto, outros têm, nessa prática extrativista, o sustento de suas famílias, já que a atual conjuntura econômica do país não oferece melhor sorte aos mesmos. Isto torna o problema ainda mais complexo. Saber avaliar o ponto exato de equilíbrio entre a necessidade humana de sobrevivência e a preservação ambiental é um desafio proposto a toda sociedade.

\section{Referências bibliográficas}

CASTAÑEDA, C., ADDAD, J. E., LICCARDO, A. Gemas de Minas Gerais. Belo Horizonte: Lastro, SBG, Unicentro Newton Paiva, 2001. 280p. il.

GANDINI, A. L. Mineralogia, inclusões fluidas e aspectos genéticos do topázio imperial da região de Ouro Preto, Minas Gerais. 1994. 212 f. il. São Paulo: Instituto de Geociências, Universidade de São Paulo, 1994. (Dissertação de mestrado em Geologia).

INSTITUTO BRASILEIRO DE MINERAÇÃO. Mineração \& meio ambiente. Brasília: IBRAM, 1992. 126p. il.

MIRANDA, J. G. D., CIPRIANI, M., MÁRTIRES, R. A. C., GIACONI, W. J. Atividades garimpeiras no Brasil: aspectos técnicos, econômicos e sociais. Rio de Janeiro: CETEM/CNPq, 1997. 61p.

RAMOS, L. F. Cachoeira do Campo, a filha pobre de Ouro Preto. Belo Horizonte: Editora São Vicente, [196_ ]. 214p. il.

SAUER, D. A., KELLER, A. S., MCCLURE, S. F. An update on imperial topaz from the Capão Mine, Minas Gerais, Brazil. Gems\&Gemology, v. 32, p. 232-241 il., winter 1996.

\section{Artigo recebido em 03/06/2004 e} aprovado em 27/09/2004. 